\title{
Metformin and FTY720 Synergistically Induce Apoptosis in Multiple Myeloma Cells
}

\author{
Yi Zhao ${ }^{a}$ Enfan Zhang ${ }^{a}$ Ning Lv $^{b}$ Liang Mac Shunnan Yao ${ }^{c}$ \\ Meidi Yan ${ }^{d}$ Fumin Zi $i^{a}$ Gang Deng ${ }^{e}$ Xinling Liu ${ }^{a}$ Jingsong $\mathrm{He}^{\mathrm{a}}$ \\ Wenjun $\mathrm{Wu}^{\mathrm{a}}$ Zhen Caia ${ }^{\mathrm{a}}$ Rui Yu
}

\begin{abstract}
aBone Marrow Transplantation Center, First Affiliated Hospital, College of Medicine, Zhejiang University, Hangzhou, 'bepartment of Pharmacy, First Affiliated Hospital, College of Medicine, Zhejiang University, Hangzhou, 'Department of Biochemistry and Molecular Biology, Zhejiang Key Laboratory of Pathophysiology, Medical School, Ningbo University, Ningbo, dDepartment of General Surgery, No. 7 Hospital of Ningbo, Ningbo, eNingbo Central Blood Station, Ningbo, China
\end{abstract}

\section{Key Words}

Multiple myeloma • Metformin • FTY720 - Apoptosis - ER stress • Mitochondrial membrane potential $\cdot$ ROS

\begin{abstract}
Background/Aims: Patients with multiple myeloma $(\mathrm{MM})$ invariably relapse with chemotherapy-resistant disease, underscoring the need for new therapeutic options that bypass these resistance mechanisms. Metformin is a widely prescribed antidiabetic drug with direct antitumor activity against various tumor cell lines. FTY720, also known as fingolimod, is an immune-modulating agent approved by the FDA as oral medication to treat the relapsing form of multiple sclerosis (MS). In recent years, FTY720 has attracted attention due to its anti-tumor activity. To explore an optimized combinational therapy, interactions between metformin and FTY720 were examined in MM cells. Methods: MTT assays were employed to assess the viability of MM cells. An apoptotic nucleosome assay was employed to measure apoptosis. Loss of mitochondrial membrane potential (MMP, $\Delta \Psi \mathrm{m})$ and cellular levels of ROS were measured by flow cytometry. qRT-PCR was used to analyze the expression of mRNAs. Western blotting assays were applied to measure the levels of proteins involved in different signaling pathways. Results: Coadministration of metformin and FTY720 synergistically inhibited the proliferation of MM cells. Increased levels of apoptosis, activation of caspase-3 and cleavage of PARP were detected after cotreatment with metformin and FTY720. These events were associated with modulation of Bcl-2 proteins, loss of MMP, ER stress induction, and inhibition of the PI3K/AKT/mTOR signaling pathway. The metformin/FTY720 regimen markedly induced ROS generation; moreover, apoptosis, ER stress and inhibition of PI3K/AKT/ mTOR were attenuated by the ROS scavenger NAC. Conclusions: Exposure to metformin in combination with FTY720 potently induces apoptosis in MM cells in a ROS-dependent manner, suggesting that a strategy combining these agents warrants further investigation in MM.
\end{abstract}

\begin{tabular}{|c|c|}
\hline & $\begin{array}{l}\text { (c) } 201 \\
\text { Publis } \\
\end{array}$ \\
\hline $\begin{array}{l}\text { Zhen Cai } \\
\text { and Rui Yu }\end{array}$ & $\begin{array}{l}\text { Bone Marrow Transplantation Center, First Affiliated Hospital } \\
\text { College of Medicine, Zhejiang University, Hangzhou, (China) } \\
\text { E-Mail caiz@zju.edu.cn, yurui@nbu.edu.cn }\end{array}$ \\
\hline
\end{tabular}

\section{KARGER}




\section{Cellular Physiology Cell Physiol Biochem 2018;48:785-800

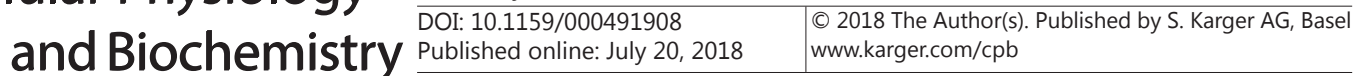 \\ Zhao et al.: Metformin and FTY720 Have Synergistic Effects Against Multiple Myeloma}

\section{Introduction}

Multiple myeloma (MM), also known as plasma cell myeloma, is a malignant cell proliferation disorder and accounts for approximately $10 \%-15 \%$ of all hematological cancers [1]. Well-established characteristics of MM include the clonal expansion of plasma cells in the bone marrow and excessive accumulation of serum immunoglobulin [2]. With the development of novel agents and high-dose chemotherapy, the median survival time of MM patients has greatly improved over the past several decades [3]. However, MM is still largely incurable, and its median survival remains at 5 to 7 years, primarily due to the development of chemo-resistance and patients often suffering from side effects and comorbidities [4]. Therefore, identification of novel therapeutic agents against MM is urgently needed.

Metformin is an oral hypoglycemic agent belonging to the biguanide family and is well-known for its beneficial effects in the treatment of type II diabetes mellitus [5]. Epidemiological studies have shown that there is an association between type II diabetes mellitus and a higher risk of cancer incidence and mortality [6]. Therefore, antidiabetic agents might have beneficial effects in the treatment of cancer. For example, diabetes is associated with an increased MM incidence, and metformin has been found to possess the ability to inhibit the development of MM both in vitro and in vivo [7, 8]. Amounting evidence indicates that metformin also possesses anti-tumor effects against different cancers such as melanoma, colon cancer, ovarian cancer, lung cancer, bladder cancer and prostate cancer [9-11]. Moreover, several preclinical and clinical studies have shown the beneficial effects of metformin in cancer treatment, and few serious adverse events were observed $[12,13]$.

FTY720, a sphingosine analogue and a sphingosine-1-phosphate (S1P) receptor antagonist, is a fungal metabolite identified in traditional Chinese herbal medicine [14]. Currently, FTY720 has been approved by both the FDA and the EMA for the treatment of multiple sclerosis (MS), and it is currently the only available S1P receptor-modulating drug. Over the past several years, several studies have found that FTY720 was also effective in the inhibition of several cancers such as cervical cancer, hepatocellular carcinoma, breast cancer, glioma and lung cancer [15-19]. FTY720 can be taken up by the cells and phosphorylated by SK2 to form FTY720-phosphate (FTY720-P), which is a mimetic of S1P [20, 21]. FTY720-P can interact with several S1P receptors and preferentially induce internalization and proteasomal degradation of ${\mathrm{S} 1 \mathrm{P}_{1}}_{1}$ [21]. FTY720 has also been shown to enhance the effects of chemotherapeutic agents against various cancers both in vitro and in vivo [22]

Growing evidence suggests that the combination of different anti-tumor agents may produce synergistic effects, resulting in lower doses of each agent used in the combination and thereby reducing the side effects caused by the agents used in mono-therapy. In the present study, we found that metformin and FTY720 could act synergistically to repress viability and induce apoptosis of MM cells, and the underlying mechanisms for this effect were investigated.

\section{Materials and Methods}

\section{Cell culture and reagents}

Human MM cell lines U266, RPMI8226, LP-1 and NCI-H929 were obtained from the American Type Culture Collection (ATCC) and cultured in RPMI 1640 medium supplemented with $10 \%$ fetal bovine serum (FBS, Gibco), $2 \mathrm{mM} \mathrm{L-glutamine} \mathrm{(Gibco)} \mathrm{and} 1 \%$ penicillin/streptomycin (Gibco) at $37^{\circ} \mathrm{C}$ in a $5 \% \mathrm{CO}_{2}$ incubator. 3-(4, 5-dimethylthiazol-2-yl)-2, 5 diphenyltetrazolium bromide (MTT), NAC, and Metformin were purchased from Sigma-Aldrich (St. Louis, USA). FTY720 was purchased from Selleck Chemicals (Houston, USA).

MTT assay

Cell viabilities were assayed by the MTT assay as described earlier [23]. Briefly, cells were seeded in 96-well plates at a density of $2 \times 10^{4} /$ well in $100 \mu \mathrm{L}$ culture medium. After treatment, $10 \mu \mathrm{l} \mathrm{of} 5 \mathrm{mg} / \mathrm{ml} \mathrm{MTT}$ 


\section{Cellular Physiology Cell Physiol Biochem 2018;48:785-800 \begin{tabular}{c|c} 
DOI: 10.1159/000491908 & $\begin{array}{l}\text { O } 2018 \text { The Author(s). Published by S. Karger AG, Basel } \\
\text { www.karger.com/cpb }\end{array}$
\end{tabular} \\ Zhao et al.: Metformin and FTY720 Have Synergistic Effects Against Multiple Myeloma}

(Sigma, St. Louis, MO, USA) was added to each well, and the cells were further incubated for $4 \mathrm{~h}$ at 370. Finally, another $150 \mu \mathrm{l}$ of DMSO was added to each well, and the absorbance was measured by an ELISA Microwell Reader (BioTek Co, USA). Wells without cells (DMSO alone) were used as blanks, and experiments were repeated at least 3 times. Data represent the mean \pm SD of 3 independent experiments. The results of the combined treatment (combination index, CI) were analyzed using the CalcuSyn software program according to the Chou-Talalay equation, and the value of the combination index (CI) for the combination treatment was quantitatively used to define the effect with $\mathrm{CI}<1$ (synergism), $\mathrm{CI}=1$ (additivity), and $\mathrm{CI}>$ 1 (antagonism).

\section{Apoptosis assay}

For the quantification of apoptotic cells, an Apoptotic Nucleosome ELISA kit from Calbiochem (Cambridge, MA) was applied. This kit uses a photometric enzyme immunoassay that quantitatively determines the formation of cytoplasmic histone-associated DNA fragments (mono and oligonucleosomes) after apoptotic cell death. The induction of apoptosis was evaluated by assessing the enrichment of nucleosomes in cytoplasm and was determined exactly as described in the manufacturers' protocol.

\section{Caspase-3 activity assay}

Caspase- 3 activity was assayed by using the Apo-ONE homogeneous caspase- $3 / 7$ assay kit (Promega, WI, USA) according to the manufacturer's guidelines. Briefly, equal amounts of medium and Apo-ONE caspase reagent (1:100 profluorescent substrate and lysis buffer) were added to the cells, and the mixture was incubated for $5 \mathrm{~h}$. Fluorescence (excitation, $485 \mathrm{~nm}$; emission, $512 \mathrm{~nm}$ ) was measured using the fluorescence plate reader. Background fluorescence was determined with medium alone and subtracted from all experimental values.

\section{Detection of mitochondrial membrane potential (MMP)}

The mitochondrial membrane potential was monitored using Rhodamine-123 fluorescent dye (Sigma), a cell-permeable cationic dye, which preferentially enters into mitochondria due to the highly negative mitochondrial membrane potential $(\Delta \Psi \mathrm{m})$. Depolarization of $\Delta \Psi \mathrm{m}$ results in the loss of Rhodamine-123 from the mitochondria and a decrease in intracellular fluorescence. After treatment, cells were harvested and washed with PBS. The cell pellets were then resuspended in $5 \mathrm{~mL}$ of fresh incubation medium containing $2.0 \mu \mathrm{M}$ rhodamine 123 and incubated at $37^{\circ} \mathrm{C}$ for $20 \mathrm{~min}$ and then analyzed by flow cytometry (Becton Dickinson, San Jose, CA).

\section{Transfection}

MM cells were transiently transfected with control short interfering RNA (siRNA), ATF4 siRNA, myrAkt construct using the Lipofectamine 2000 reagent (Life technologies) according to the manufacturer's protocol. Briefly, $4 \mu \mathrm{l}$ of $20 \mu \mathrm{M}$ siRNA or plasmid (10 ng) was mixed with $200 \mu \mathrm{l}$ of Opti-MEM. Lipofectamine $2000(4 \mu \mathrm{l})$ was diluted in $200 \mu \mathrm{l}$ of Opti-MEM and incubated at room temperature for $5 \mathrm{~min}$. After incubation, the diluted Lipofectamine 2000 was mixed with the diluted siRNA and further incubated for $20 \mathrm{~min}$ at room temperature. A total $400 \mu \mathrm{l}$ of the siRNA/plasmid- Lipofectamine 2000 complex was applied to each well of the cultured cells at approximately 50\%-70\% confluence in 6-well microplates.

\section{Measurement of ROS}

Generation of ROS was measured by 2',7'-dichlorofluorescin diacetate (DCFH-DA, Sigma-Aldrich) which is converted to fluorescent 2',7'-dichlorofluorescin (DCF) in the presence of peroxides as described earlier [24].

\section{Quantitative RT-PCR}

Total RNA was extracted using TRIzol reagent (Ambion, USA). RNA quantification and mRNA integrity were tested with a NanoDrop spectrophotometer (Thermo Fisher, USA) and agarose gel electrophoresis. Next, cDNA was generated from $1 \mu \mathrm{g}$ total RNA by using TransScript First-strand cDNA Synthesis SuperMix kit (Life Technologies) following the manufacturer's guide. Real time PCR analysis was carried out with the SYBR1 Green PCR Master Mix with the following primers: GAPDH, forward:

5'-GACAGTCAGCCGCATCTTCT-3'; reverse: TTAAAAGCAGCCCTGGTGAC. 


\section{Cellular Physiology Cell Physiol Biochem 2018;48:785-800 \begin{tabular}{l|l} 
DOI: 10.1159/000491908 & $\begin{array}{l}\text { O } 2018 \text { The Author(s). Published by S. Karger AG, Basel } \\
\text { www.karger.com/cpb }\end{array}$
\end{tabular} \\ Zhao et al.: Metformin and FTY720 Have Synergistic Effects Against Multiple Myeloma}

ATF6, forward: 5'-AAGCCCTGATGGTGCTAACTGAA-3'; reverse: 5'-CATGTCT

ATGAACCCATCCTCGAA-3'; GRP78, forward: 5'-GAAAGAAGGTTACCCAT

GCAGT-3'reverse:5'-CAGGCCATAAGCAATAGCAGC-3';CHOP,forward:5'-GGAAACAGAGTGGTCATTCCC-3', reverse: 5'-CTGCTTGAGCCGTTCATTC

TC-3'. Relative gene expression was calculated using the $2-\Delta \Delta \mathrm{Ct}$ method. The expression of genes of interest was normalized to GAPDH.

Western blot assay

Cells were harvested after treatment, washed 3 times with PBS and lysed in CHAPS lysis buffer (Cell Signaling Technology). The concentration of protein was measured using the BCA protein assay kit, and loading buffer was added to the samples. The samples were subjected to $12 \%$ SDS-PAGE; then proteins were transferred onto PVDF membranes (Millipore). After blocking with 5\% non-fat milk at room temperature for $1 \mathrm{~h}$, PVDF membranes were incubated with primary antibodies overnight at $4^{\circ} \mathrm{C}$. The following antibodies against these proteins were used: Caspase-3, PARP, Mcl-1, Bcl-xl, Bcl-2, Bax, Smac/DIABLO, Cytochrome C, ATF-4, phospho-IRE1 $\alpha$, IRE1 $\alpha$, phosphor-eIF2 $\alpha$, eIF2 $\alpha$, phosphor-Akt, Akt, phosphor-PI3K, PI3K, mTOR, and GAPDH, which were all purchased from Cell Signaling Technologies (Danvers, USA). Next, the membranes were incubated with the corresponding secondary antibodies for $1 \mathrm{~h}$ at room temperature.

Finally, the proteins were detected by enhanced chemiluminescence, and densitometric analysis was performed using ImageJ software. The cytosolic fraction of the cells was purified as described earlier [25].

\section{Statistical analysis}

All numerical data are presented as the mean \pm S.D. for at least three independent measurements. Statistical analysis of two means was performed with Student's t-test. Three or more means were analyzed with one-way ANOVA and Bonferroni's post hoc test. A probability value of less than 0.05 was considered to be statistically significant.

\section{Results}

The combination of metformin and FTY720 synergistically inhibited the viability of MM cells

We first examined the proliferation of 4 MM cell lines (U266, RPMI8226, LP-1 and NCI-H929) in response to metformin and/or FTY720. Treatment of metformin and FTY720 alone reduced the viability of MM cell lines in a dose-dependent manner over 48 h of treatment (Fig. 1A). However, the combination of metformin and FTY720 significantly decreased the viability of MM cells compared to the treatment with metformin alone and FTY720 alone (Fig. 1A). The calculated IC50 values of metformin and FTY720 in different treatment are listed in Table 1 and 2. Interestingly, the CI (combination index) values were below 0.8 at almost all fraction-affected points, implying strong synergy between metformin and FTY720 in all four MM cell lines (Fig. 1B).

The combination of metformin and FTY720 induces synergistic apoptosis in MM cells

To examine the role of apoptosis in the inhibitory effect of metformin and FTY720 in combination, cell apoptosis was analyzed by Nucleosome ELISA as described earlier [26]. We found that the levels of nucleosomes were significantly increased by the combination of metformin $(20 \mathrm{mM})$ and FTY720 $(20 \mu \mathrm{M})$ compared to the treatment with metformin $(20$ $\mathrm{mM})$ or FTY720 $(20 \mu \mathrm{M})$ alone (Fig. 2A). Next, we investigated the activity of caspase- 3 and found that the activity of caspase- 3 was also significantly increased after co-treatment with metformin (20 mM) and FTY720 (20 $\mu$ M) (Fig. 2B). Moreover, we measured the activation of caspase-3 by western blot after treatment with metformin and FTY720. As shown in Fig. 2B, the protein levels of procaspase- 3 were remarkably decreased while the cleaved caspase- 3 and PARP were significantly increased after the co-treatment with metformin $(20 \mathrm{mM})$ and FTY720 $(20 \mu \mathrm{M})$ compared with the treatment with metformin $(20 \mathrm{mM})$ or FTY720 $(20 \mu \mathrm{M})$ alone. 
Table 1. IC50 value of FTY720 in combination with Metformin in U266, RPMI8226, LP-1 and NCI-H929 cells. Data are presented as mean \pm SD, FTY: FTY720; Met: Metformin

\begin{tabular}{lcccc}
\hline FTY $\mu \mathrm{M}$ & Met 0 mM & Met $5 \mathrm{mM}$ & Met $10 \mathrm{mM}$ & Met 20 mM \\
\hline U266 & $34.2 \pm 4.2$ & $13.8 \pm 3.7$ & $10.2 \pm 2.4$ & $4.3 \pm 3.3$ \\
RPMI8226 & $40.7 \pm 3.5$ & $9.4 \pm 5.1$ & $6.7 \pm 1.8$ & $3.6 \pm 0.7$ \\
LP-1 & $47.3 \pm 8.4$ & $11.4 \pm 4.4$ & $6.2 \pm 2.1$ & $4.2 \pm 1.1$ \\
NCI-H929 & $72.4 \pm 7.3$ & $8.3 \pm 6.5$ & $5.4 \pm 3.2$ & $2.7 \pm 0.8$ \\
\hline
\end{tabular}

Table 2. IC50 value of Metformin in combination with FTY720 in U266, RPMI8226, LP-1 and NCI-H929 cells

\begin{tabular}{lcccc}
\hline Met mM & FTY 0 $\mu \mathrm{M}$ & FTY 5 $\mu \mathrm{M}$ & FTY $10 \mu \mathrm{M}$ & FTY 20 $\mu \mathrm{M}$ \\
\hline U266 & $27.3 \pm 6.2$ & $22.2 \pm 3.1$ & $13.4 \pm 4.6$ & $3.9 \pm 22$ \\
RPMI8226 & $52.4 \pm 5.3$ & $16.4 \pm 2.8$ & $8.7 \pm 3.4$ & $4.3 \pm 1.1$ \\
LP-1 & $44.2 \pm 6.8$ & $13.2 \pm 2.2$ & $9.4 \pm 4.2$ & $3.4 \pm 0.9$ \\
NCI-H929 & $32.9 \pm 7.1$ & $10.3 \pm 1.4$ & $4.7 \pm 2.3$ & $1.6 \pm 0.5$ \\
\hline
\end{tabular}

Fig. 1. Metformin and FTY720 in combination synergistically reduces the viability of MM cells.Four MM cell lines (U266, RPMI8226, LP-1 and NCI-H929) were treated with the indicated doses of metformin (Met) and FTY720 (FTY) alone or in combination for $48 \mathrm{~h}$, then cell viability was measured by MTT assay $\left({ }^{*} \mathrm{P}<0.05,{ }^{* *} \mathrm{P}<0.01 ;{ }^{* * *} \mathrm{P}<0.001\right.$ vs the first column in each group). Data are presented as the mean $\pm \mathrm{SD}$. (B) Combination index (CI) of metformin and FTY720 in four MM cell lines were calculated using the ChouTalalay method (CompuSyn). Fa: Fraction affected.

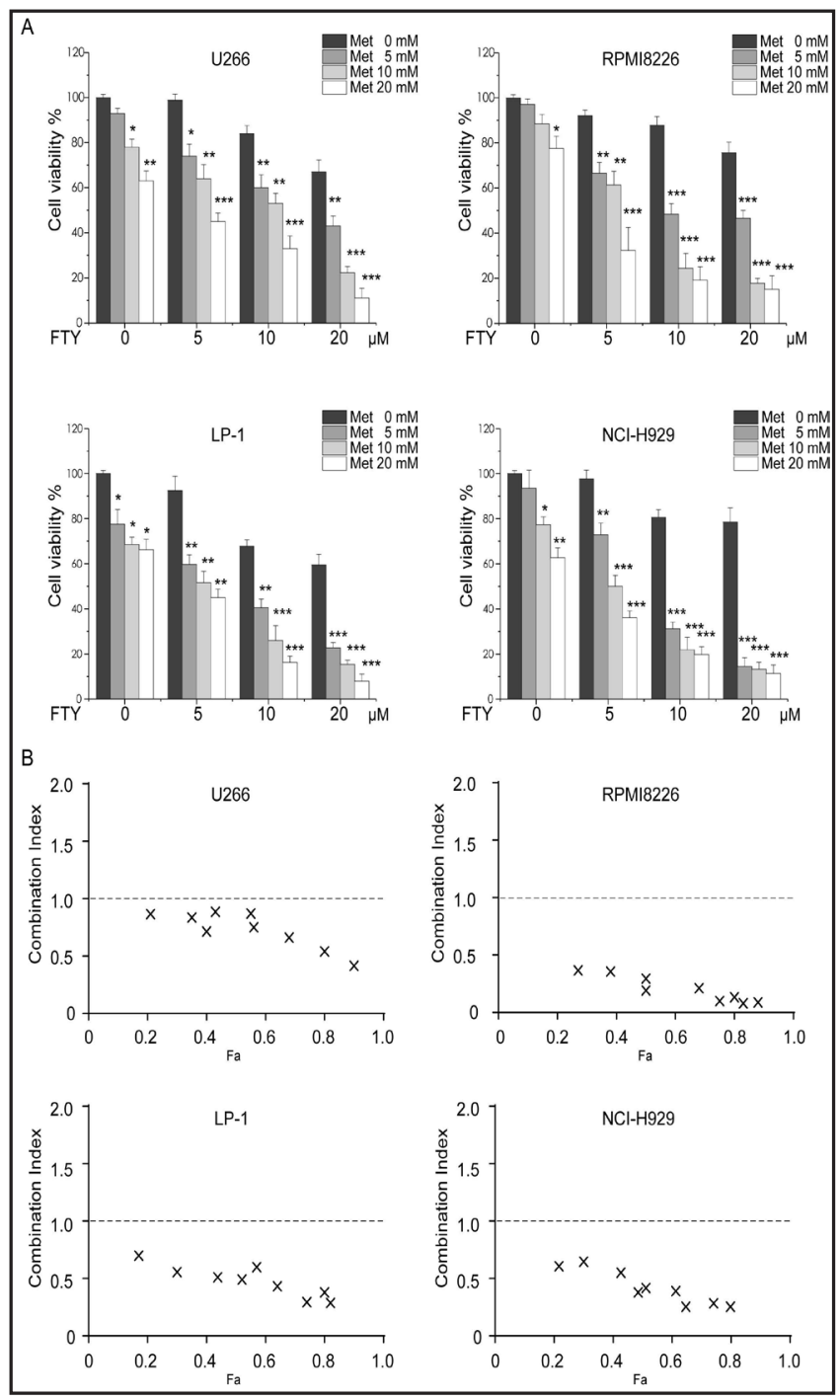


The combination of metformin and FTY720 synergistically modulates the Bcl-2 proteins, release of mitochondrial proteins and causes loss of MMP

Accumulating evidence indicates that the process of apoptosis is subjected to the regulation of $\mathrm{Bcl}-2$ family proteins [27]. Previous studies indicated that both metformin and FTY720 exerted their antitumor effects via at least partly affecting the levels of $\mathrm{Bcl}-2$ proteins $[28,29]$. Therefore, we asked whether the combination of metformin and FTY720 could affect the levels of $\mathrm{Bcl}-2$ proteins. As shown in Fig. 3A, treatment with metformin or FTY72 alone repressed the levels of anti-apoptotic $\mathrm{Bcl}-2$ proteins Mcl-1, Bcl-xl and Bcl-2, while co-treatment with metformin and FTY720 inhibited these proteins to a greater extent. It is noteworthy that either metformin or FTY720 alone had little effect on the pro-apoptotic Bcl-2 protein Bax (Fig. 3A). However, the combination of metformin and FTY720 led to an up-regulation of Bax (Fig. $3 \mathrm{~A})$. We also found that the combination of metformin and FTY720 could lead to the release of cytochrome $\mathrm{c}$ and Smac/DIABLO to a greater extent than the single treatment with metformin or FTY720

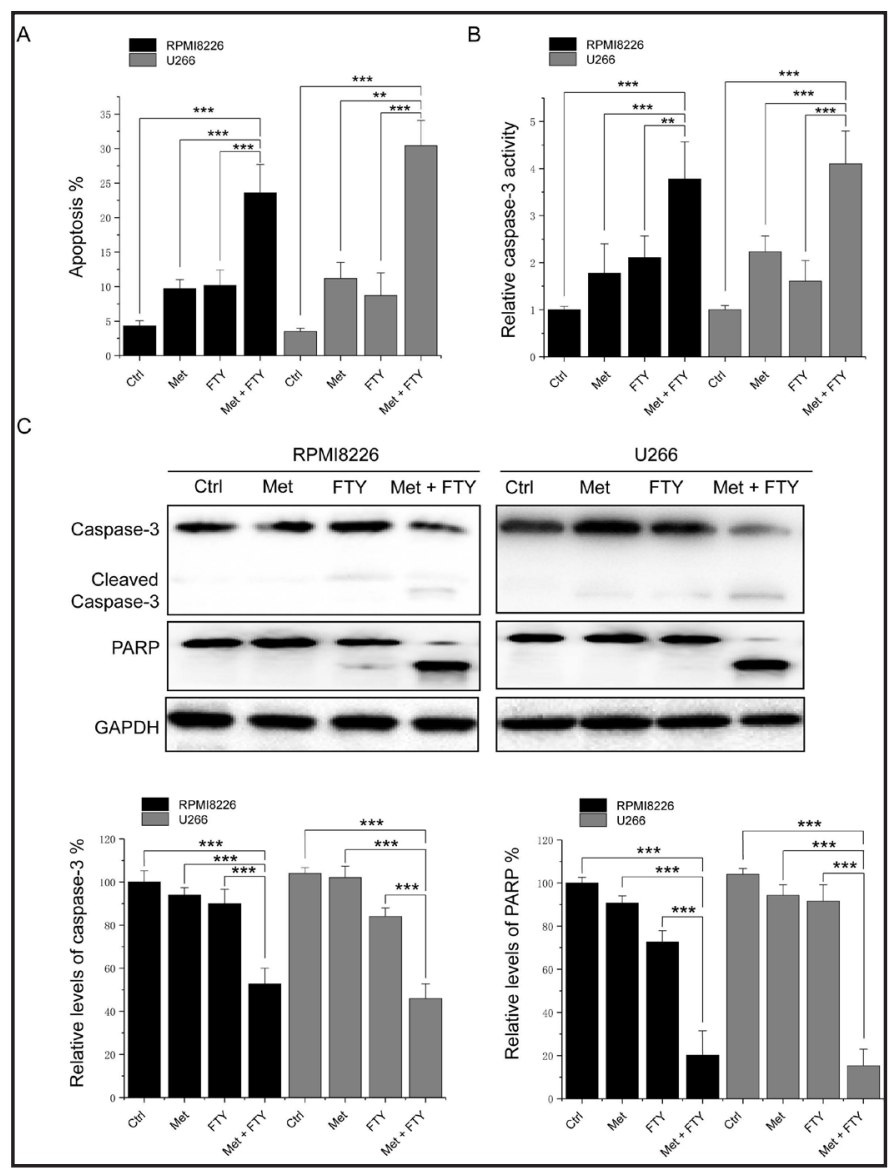

Fig. 2. Metformin and FTY720 in combination induce synergistic apoptosis in MM cells. MM cells RPMI8226 and U266 were treated with metformin (Met, $20 \mathrm{mM}$ ), FTY720 (FTY, $20 \mu \mathrm{M}$ ), or metformin plus FTY720 (Met + FTY, $20 \mathrm{mM}+20 \mu \mathrm{M}$ ) for $24 \mathrm{~h}$. (A) Cellular apoptosis rates were measured using the Apoptosis Nucleosome ELISA assay. (B) Caspase-3 activity was assayed. (C) The protein levels of caspase-3, PARP were measured by the western blot assay. GAPDH was used as a loading control. The experiments were repeated at least three times and representative images are shown. Data are presented as the mean $\pm \mathrm{SD}$. ${ }^{*} \mathrm{P}<0.05 ;{ }^{*} \mathrm{P}<0.01$; $* * * \mathrm{P}<0.001$.

(Fig. 3B). The disruption of mitochondrial integrity is one of the key events in apoptosis. To assess whether metformin and FTY720 affects the function of mitochondria, the mitochondrial membrane potential (MMP) was analyzed by flow cytometry. As seen in Fig. 3C, the combination of metformin and FTY720 triggered a greater decrease of MMP than the treatment with metformin or FTY720 alone.

Taken together, these results indicate that the synergistic effects of metformin and FTY720 are at least partially mediated via modulation of Bcl-2 family proteins, release of mitochondrial proteins and alterations of MMP in MM cells.

\section{Metformin and FTY720 synergistically induce ER stress in MM cells}

Endoplasmic reticulum (ER) stress triggers various processes affecting cellular function and fate, including apoptosis, which contributes to many anti-MM effects from such agents as toyocamycin, bortezomib and proteasome inhibitor PS-341 [30-32]. Therefore, we asked

\section{KARGER}




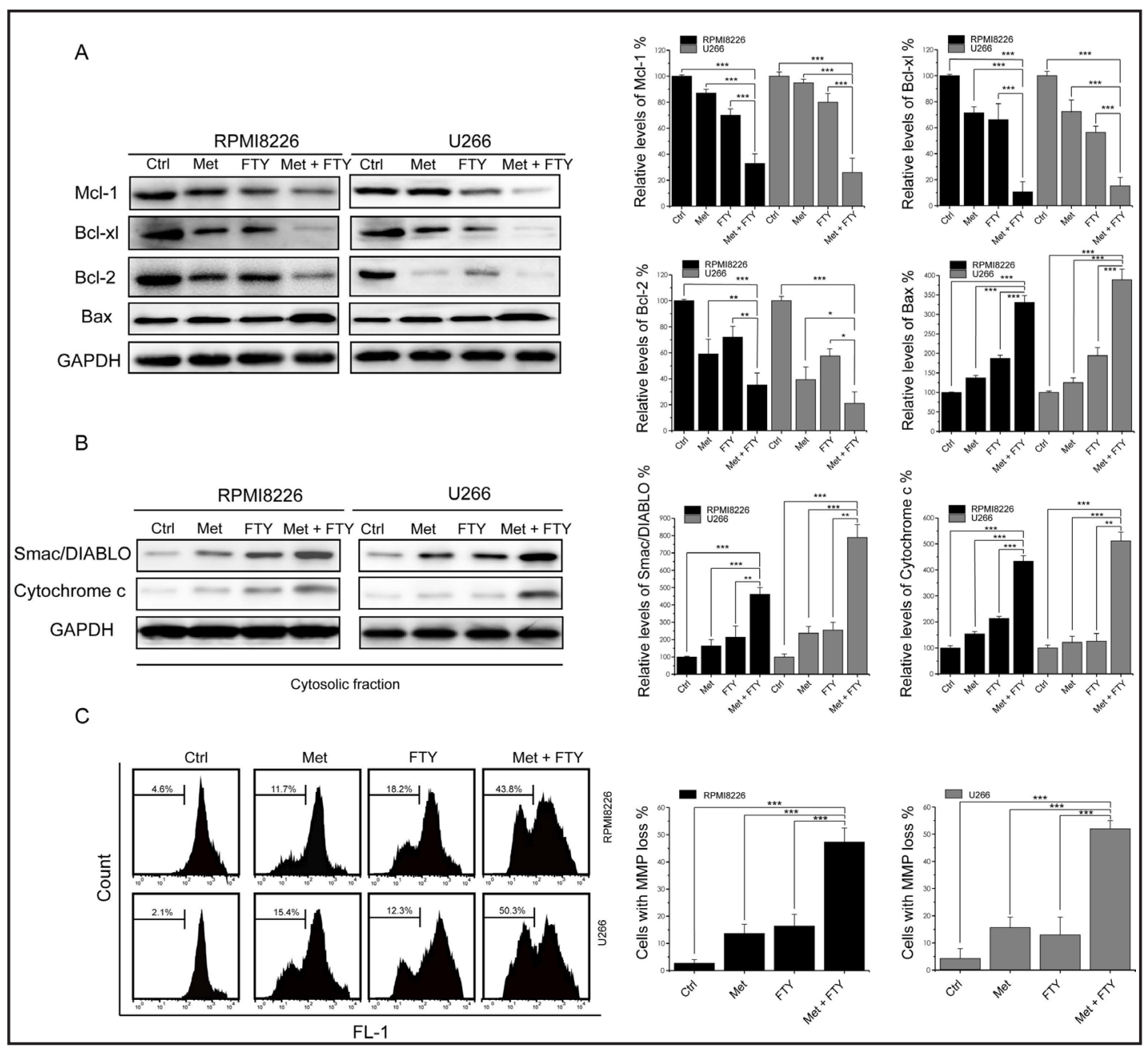

Fig. 3. Metformin and FTY720 synergistically affect the levels of Bcl-2 proteins, release of mitochondrial proteins and loss of MMP in MM cells.MM cells RPMI8226 and U266 were treated with metformin (Met, 20 mM), FTY720 (FTY, $20 \mu \mathrm{M}$ ), or metformin plus FTY720 (Met + FTY, $20 \mathrm{mM}+20 \mu \mathrm{M}$ ) for 24 h. (A) Total cellular lysates were collected and subjected to western blot analysis with the indicated antibodies. (B) Cytosolic fractions were collected and subjected to western blot analysis with the indicated antibodies. (C) The change of MMP (mitochondrial membrane potential) was measured by flow cytometry. Percentage values indicate cells with depolarized mitochondria. The experiments were repeated at least three times and representative images are shown. Data are presented as the mean $\pm \mathrm{SD}$. ${ }^{*} \mathrm{P}<0.05 ;{ }^{* *} \mathrm{P}<0.01 ;{ }^{* * *} \mathrm{P}<0.001$.

whether metformin, FTY720 and their combinations could induce ER stress. First, we examined the mRNA levels of ER stress response genes such as ATF6, GRP78, and CHOP by RT-PCR. We found that co-treatment with metformin $(20 \mathrm{mM})$ and FTY720 $(20 \mu \mathrm{M})$ for $24 \mathrm{~h}$ could greatly induce the up-regulation of ATF6, GRP78 and CHOP (Fig. 4A). Moreover, we also measured the levels of the ER stress marker ATF4, phosphorylation of IRE1 $\alpha$, and phosphorylation of eIF $2 \alpha$ by western blot. As expected, we found significantly up-regulated ATF4 in parallel with increased phosphorylation of IRE1 $\alpha$ and eIF2 $\alpha$ (Fig. 4B). To further investigate the role of ER stress in the combination effect of metformin and FTY720, we applied siRNA to knockdown ATF4, which was efficiently suppressed after transfection for $24 \mathrm{~h}$ (Fig. 4C). Interestingly, the synergistic cytotoxicity of metformin and FTY720 was significantly compromised after knockdown of ATF4 (Fig. 4D, E). These results suggest that ER stress is at least partly responsible for the synergistic anti-MM effect of metformin and FTY720. 


\section{Cellular Physiology and Biochemistry \\ Cell Physiol Biochem 2018;48:785-800 \\ \begin{tabular}{l|l}
\hline DOI: $10.1159 / 000491908$ & (C) 2018 The Author(s). Published by S. Karger AG, Basel
\end{tabular} \\ Published online: July 20, $2018 \quad$ www.karger.com/cpb}

Zhao et al.: Metformin and FTY720 Have Synergistic Effects Against Multiple Myeloma

The combination of metformin and FTY720 inhibits the PI3K/Akt/mTOR pathway in MM cells

Amounting evidence indicates that the PI3K/Akt/mTOR signaling pathway contributes to the development of various carcinomas, including MM [33]. Targeting PI3K/Akt/mTOR could be an effective strategy against MM [34]. Therefore, we examined the effects of metformin, FTY720 and their combination on the MM cells. We found that metformin or FTY720 could inhibit the PI3K/Akt/mTOR pathway, although to a lesser extent than the combination of metformin and FTY720 (Fig. 5A). To further investigate the role of the PI3K/ Akt/mTOR pathway on the effect of a combination of metformin and FTY720, we transfected RPMI8226 and U266 cells with a vector encoding constitutively active Akt (myr-Akt). Next, $12 \mathrm{~h}$ after transfection, we treated the cells with metformin and FTY720 for another $24 \mathrm{~h}$ and measured the cells viability and apoptosis. As shown in Fig. 5B, overexpression of myrAkt resulted in the constitutive activation of Akt. The MTT assay showed that constitutive activation of Akt could noticeably inhibit the anti-proliferative effect of the combination of metformin and FTY720 (Fig. 5C). Meanwhile, the synergistic apoptosis induced by the combination of metformin and FTY720 could be interfered with by the activation of Akt

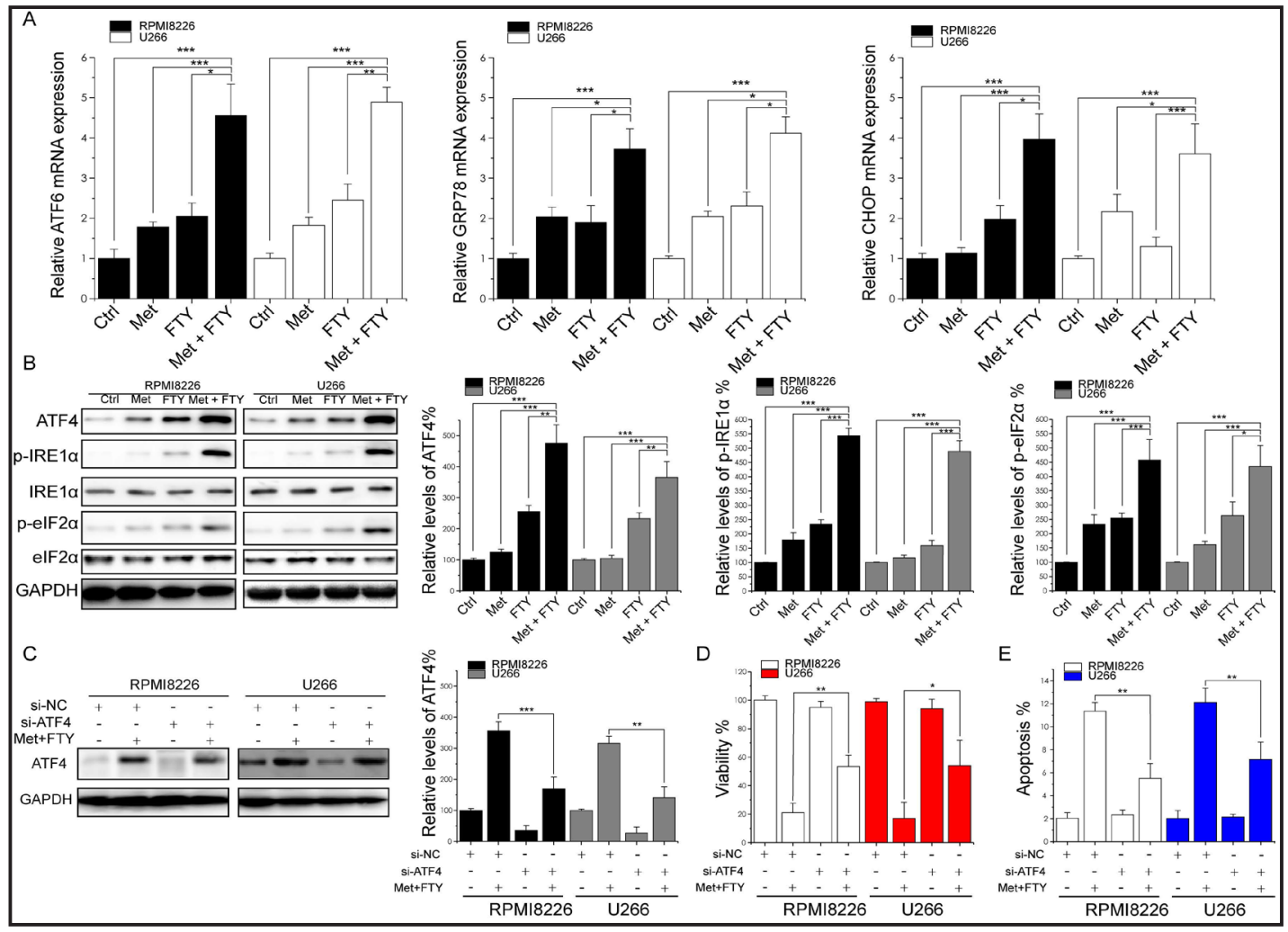

Fig. 4. Combination of metformin and FTY720 induces ER stress in MM cells.(A) MM cells RPMI8226 and U266 were treated with metformin (Met, 20 mM), FTY720 (FTY, $20 \mu \mathrm{M}$ ), or metformin (20 mM) plus FTY720 $(20 \mu \mathrm{M})(\mathrm{Met}+\mathrm{FTY})$ for $24 \mathrm{~h}$. mRNA levels of ATF6, GRP78 and CHOP were quantitatively analyzed by RTPCR. (B) Cells were treated as described above, total cellular lysates were collected and subjected to western blot analysis with the indicated antibodies. (C) RPMI8226 and U266 cells were transfected with si-NC or siATF4 in the presence or absence of metformin plus FTY720 for $24 \mathrm{~h}$, then cellular lysates were subjected to western bot with the indicated antibodies. (D) RPMI8226 and U266 cells were transfected with si-NC or siATF4 in the presence or absence of metformin plus FTY720 for $24 \mathrm{~h}$, then cell viabilities were measured by MTT assay. (E) RPMI8226 and U266 cells were transfected with si-NC or si-ATF4 in the presence or absence of metformin plus FTY720 for $24 \mathrm{~h}$, then cellular apoptosis was measured by nucleosome ELISA assay. The experiments were repeated at least three times and representative images are shown. Data are presented as the mean $\pm \mathrm{SD} .{ }^{*} \mathrm{P}<0.05 ;{ }^{* *} \mathrm{P}<0.01 ;{ }^{* *} \mathrm{P}<0.001$. 
(Fig. 5D). Taken together, these data suggest that the combination of metformin and FTY720 exerts its anti-MM function, at least partially, via inhibiting the PI3K/Akt/mTOR pathway.

The combination of metformin and FTY720 synergistically induces the generation of ROS in MM cells

As noted in previous studies, reactive oxygen species (ROS) generation may be a useful strategy to kill MM cells $[35,36]$. We thus monitored intracellular levels after treatment with metformin, FTY720 and their combination. RPMI8226 and U266 cells showed slight increases of ROS levels $24 \mathrm{~h}$ after metformin or FTY720 treatment, while considerably greater increases of ROS were observed under the combination treatment of metformin and FTY720 for $24 \mathrm{~h}$ (Fig. 6A). Meanwhile, the application of NAC (5 mM) could decrease the levels of ROS induced by metformin and FTY720 (Fig. 6A). To unveil the role of ROS in the anti-MM effects of metformin/FTY720, cell viabilities and apoptosis were measured by MTT and nucleosome ELISA assay, respectively. We found that NAC could abrogate the synergistic cytotoxicity of metformin and FTY720 (Fig. 6B, C). Moreover, the increased activity of caspase-3 induced by the combination of metformin and FTY720 could be blocked by NAC (Fig. 6D). Meanwhile, western blotting results showed that the cleavage of caspase-3, down-regulation of Bcl-2, Bcl-xl, Mcl-1 and up-regulation of Bax induced by the combination of metformin and FTY720 were also abolished by NAC. Taken together, those results indicated that the generation of ROS plays a vital role in the anti-MM effects of metformin and FTY720.

ROS is essential for the inactivation of PI3K/Akt and ER stress induced by the combination of metformin and FTY720

To further test the contribution of ROS, the effects of metformin/FTY720 on PI3K/Akt and ER stress were examined under conditions of artificially blocked production of ROS with NAC. As shown in Fig. 7A, there was a decrease of mTOR and phosphorylated PI3K, and Akt was greatly restored in the presence of NAC, which means that metformin/FTY720 induced inactivation of the PI3K/Akt/mTOR pathway is ROS-dependent. Furthermore, the ER stress

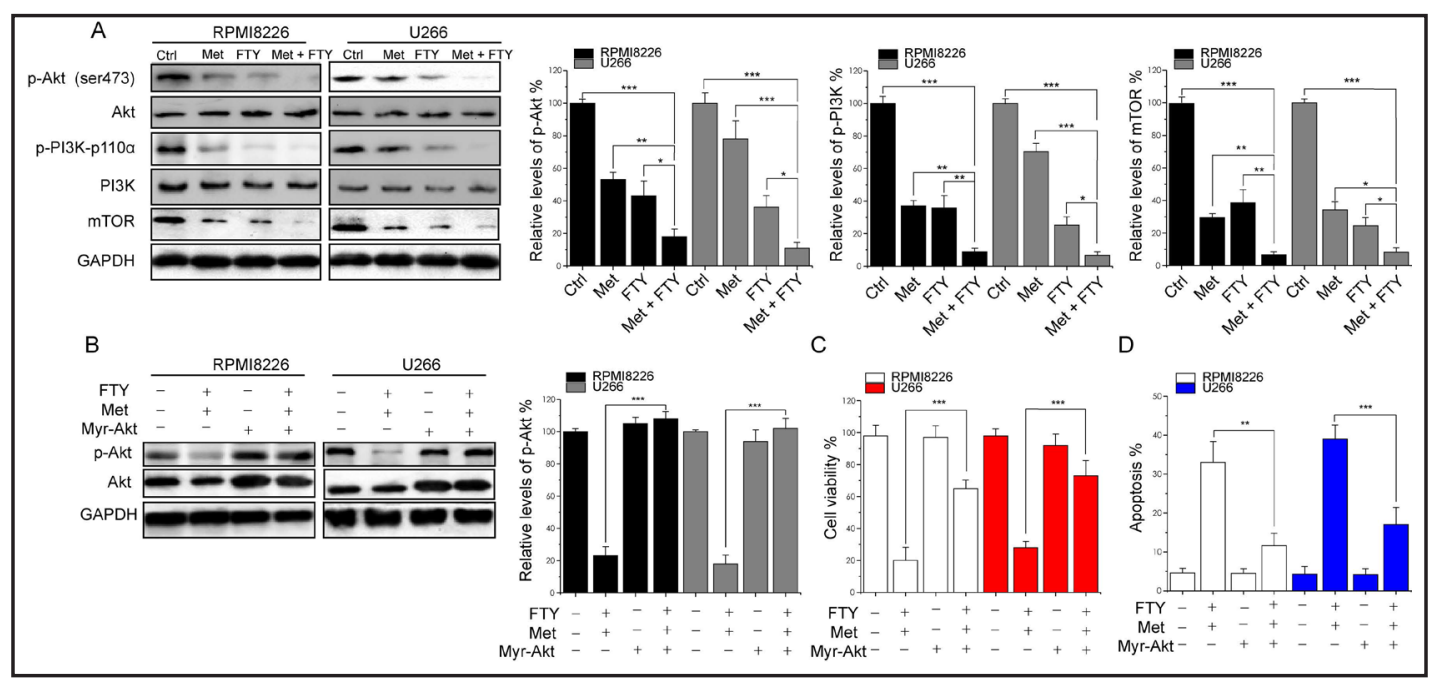

Fig. 5. Combination of metformin and FTY720 inhibits the PI3K/Akt/mTOR signaling pathway.(A) MM cells RPMI8226 and U266 were treated with metformin (Met, $20 \mathrm{mM}$ ), FTY720 (FTY, $20 \mu \mathrm{M}$ ), or metformin $(20 \mathrm{mM})$ plus FTY720 $(20 \mu \mathrm{M})(\mathrm{Met}+\mathrm{FTY})$ for $24 \mathrm{~h}$. Total cellular lysates were collected and subjected to western blot analysis with the indicated antibodies. (B) RPMI8226 and U266 were treated as indicated, then cellular lysates were subjected to the western blot analysis with the indicated antibodies. (C) RPMI8226 and U266 were treated as indicated, cell viabilities were measured by MTT assay. (D) RPMI8226 and U266 were treated as indicated, cellular apoptosis was measured by nucleosome ELISA assay. The experiments were repeated at least three times and representative images are shown. Data are presented as the mean \pm SD. ${ }^{*} \mathrm{P}<0.05$; ${ }^{* *} \mathrm{P}<0.01$; ${ }^{* * *} \mathrm{P}<0.001$. 


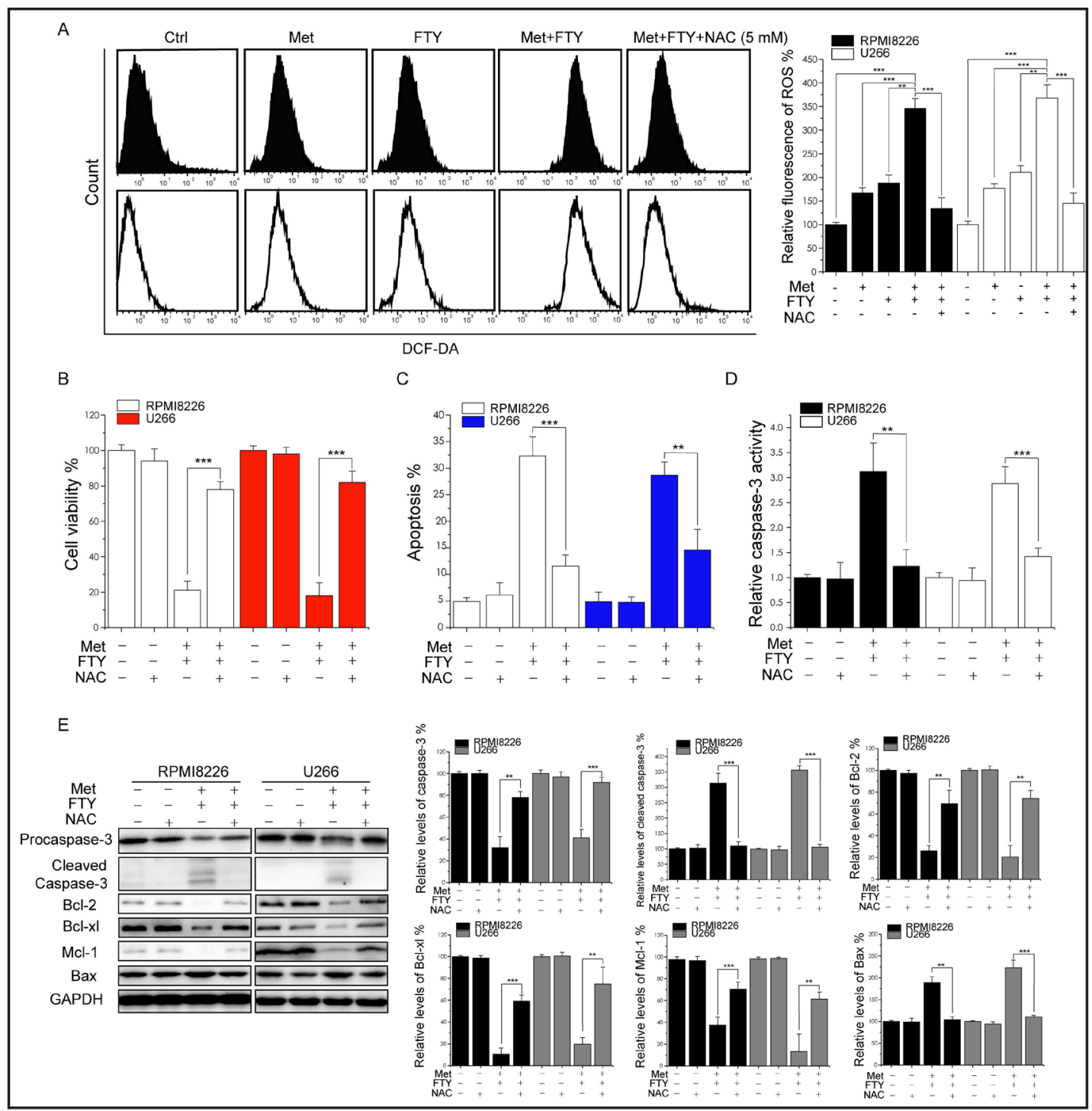

Fig. 6. Correlation of ROS generation with enhanced cytotoxicity of the metformin/FTY720 combination in MM cells.RPMI8226 and U266 cells were treated with metformin (Met, $20 \mathrm{mM}$ ), FTY720 (FTY, $20 \mu \mathrm{M}$ ), metformin $(20 \mathrm{mM})$ plus FTY720 $(20 \mu \mathrm{M})($ Met + FTY $)$ or metformin $(20 \mathrm{mM})$ plus FTY720 $(20 \mu \mathrm{M})$ in the presence of NAC (5 mM) (Met + FTY + NAC) for $24 \mathrm{~h}$. (A) The generation of ROS was evaluated by flow cytometry. (B) Cell viabilities were assayed by MTT assay. (C) Cellular apoptosis was evaluated by nucleosome ELISA assay. (D) Caspase-3 activities were assayed. (E) Total cellular lysates were collected and subjected to western blot analysis with the indicated antibodies. The experiments were repeated at least three times and representative images are shown. Data are presented as the mean $\pm \mathrm{SD} .{ }^{*} \mathrm{P}<0.05$; ${ }^{* *} \mathrm{P}<0.01$; $* * * \mathrm{P}<0.001$.

pathway was examined. The up-regulation of mRNA levels of ATF6, GRP78 and CHOP induced by metformin/FTY720 were inhibited by NAC (Fig. 7B). Moreover, the enhanced expression of ATF4, phosphorylated IRE1 $\alpha$, and phosphorylated eIF2 $\alpha$ induced by metformin/FTY720 was blocked by NAC as well (Fig. 7C). Taken together, these data indicate that the inactivation of PI3K/AKT/mTOR and activation of ER stress rely on the generation of ROS induced by metformin/FTY720 in MM cells. 


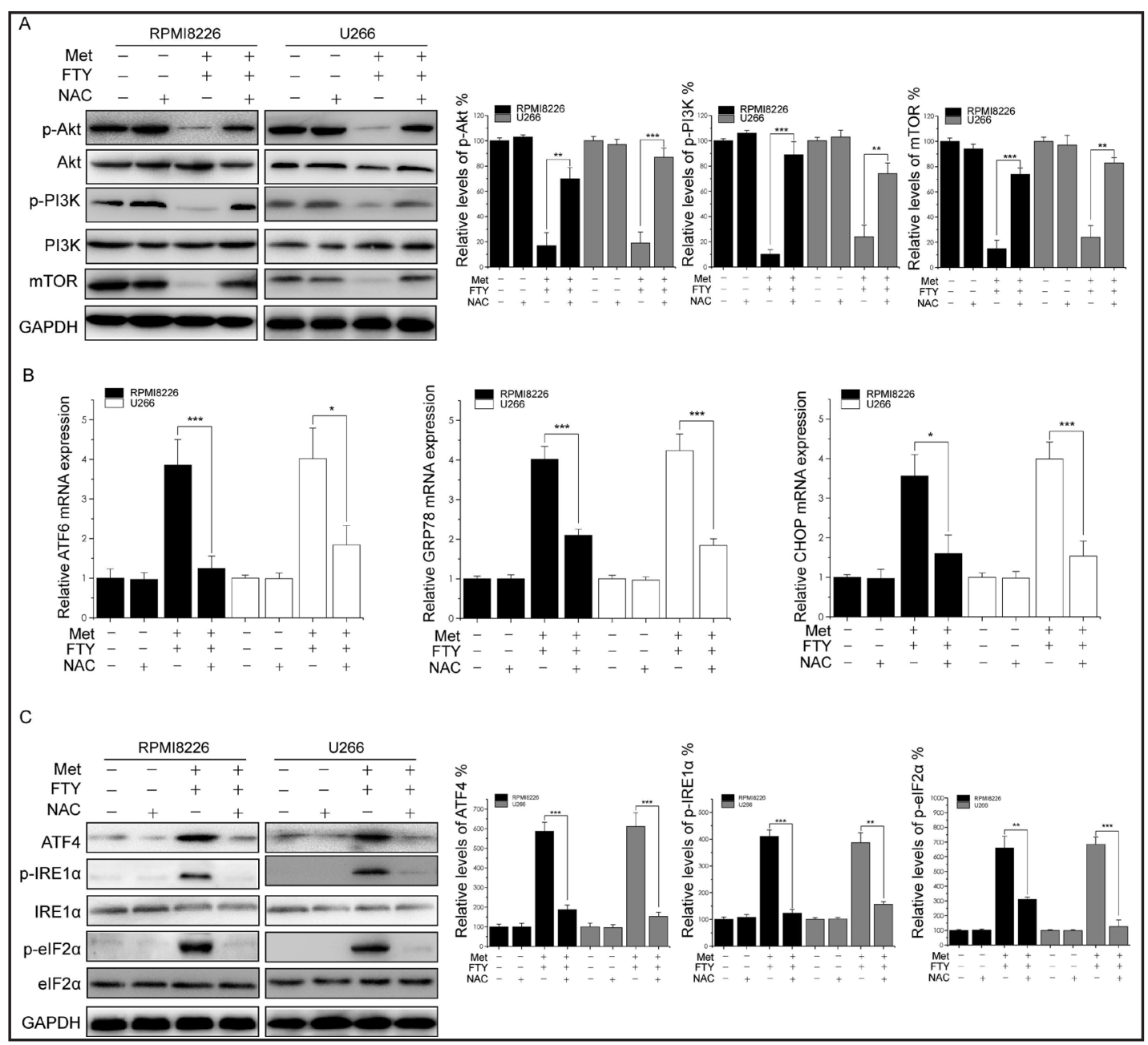

Fig. 7. Generation of ROS is critical for the inactivation of PI3K/AKT/mTOR and ER stress.RPMI8226 and U266 cells were treated with metformin $(20 \mathrm{mM})$ plus FTY720 $(20 \mu \mathrm{M})$ in the presence of NAC or not (5 $\mathrm{mM}$ ) for $24 \mathrm{~h}$. (A) Total cellular lysates were subjected to western blot analysis with the indicated antibodies. (B) Total RNA was collected and mRNA levels of ATF6, GRP78 and CHOP were quantitatively analyzed by RT-PCR. (C) Total cellular lysates were subjected to western blot analysis with the indicated antibodies. The experiments were repeated at least three times and representative images are shown. Data are presented as the mean $\pm \mathrm{SD}$. ${ }^{*} \mathrm{P}<0.05 ;{ }^{* *} \mathrm{P}<0.01 ;{ }^{* * *} \mathrm{P}<0.001$.

\section{Discussion}

Currently, there is a lack of curative therapies for MM and novel therapeutic approaches are urgently needed. Combination therapy is an important strategy for improving therapeutic outcomes and reducing the side-effects of anticancer agents. Here, the anti-MM activity of a metformin and FTY720 combination was evaluated. Our findings showed a strong ability of the combination to reduce MM cell viability and induce apoptosis. Furthermore, the ROSdependent activation of ER stress and inhibition of PI3K/AKT/mTOR were both involved in the combination effects of metformin and FTY720.

We found that metformin and FTY720 single treatments exhibited antiproliferative effects against cultured MM cell lines (U266, RPMI8226, LP-1 and NCI-H929) in a dosedependent manner. Our findings are consistent with previous studies that indicated the inhibitory effects of metformin and FTY720 on the viability of various MM cell lines [3739]. The combination of metformin and FTY720 dramatically inhibited cell viability in MM cells compared with the single treatment. Moreover, we also found that metformin and

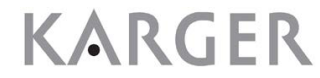




\section{Cellular Physiology and Biochemistry

FTY720 synergistically induced apoptosis in MM cells. Apoptosis can be trigged mainly via two pathways, namely, the extrinsic pathway and the intrinsic pathway [23]. In previous studies, it has been found that metformin induces apoptosis mainly via the intrinsic pathway in MM cells [37]. Similarly, FTY720 induced apoptosis in MM cells that was dependent on the activation of the intrinsic pathway [39]. Mechanistic studies revealed that the activation of intrinsic pathway was enhanced by the combination of metformin and FTY720 since the release of mitochondrial proteins because the loss of MMP was up-regulated. Moreover, the levels of anti-apoptotic Bcl-2 proteins, such as Mcl-1, Bcl-2 and Bcl-xl, were also significantly repressed by the co-treatment with metformin and FTY720. Previous studies have indicated that Mcl-1 is an essential survival protein overexpressed in myeloma cells and is associated with a poor prognosis [40]. Mcl-1 silencing has been found to elicit tumor regression and cell death in various cancer models including MM [41]. Therefore, our findings provide a rationale for a novel strategy to target Mcl-1 in MM.

ER is a vital site for protein folding, processing, quality control and trafficking [42]. ER stress occurs when ER homeostasis is lost due to an overload of protein folding in the ER [43]. In the present study, multiple ER stress markers such as GRP78, ATF6, CHOP, ATF4, phospho-IRE1 $\alpha$, and phospho-eIF2 $\alpha$ were significantly up-regulated after the co-treatment with metformin and FTY720. Moreover, knockdown of ATF4 attenuated the synergistic effects of metformin and ATF4. These findings demonstrated that ER stress is elevated by the combination of metformin and FTY720. In previous studies, metformin has been found to induce ER stress in various carcinoma cells, such as liver, prostate, and head and neck squamous cell carcinoma [44-46]. Meanwhile, several studies determined that metformin attenuates ER-stress in pancreatic beta and cardiac epithelial cells $[47,48]$. This discrepancy may be due to the use of different cell types, and further investigation is needed. Since MM cells actively produce immunoglobulin and address protein loads, they require strict regulation of ER stress for survival and they are prone to ER stress [49]. Metformin and FTY720 synergistically inducing ER stress may have great potential in the treatment of MM.

It is well-documented that the $\mathrm{PI} 3 \mathrm{~K} / \mathrm{AKT} / \mathrm{mTOR}$ signaling pathway is constitutively activated and is a vital regulator of proliferation and development in various carcinomas, including MM [50]. Previous evidence indicates that the PI3K/Akt/mTOR signaling pathway also plays essential roles in regulating cell survival and apoptosis via suppressing ER stressinduced cell death [51]. Inhibition of PI3K/AKT/mTOR signaling or dual inhibition of PI3K and mTOR can be applied as therapeutic strategies for MM treatment [34, 52]. In previous studies, either metformin or FTY720 could inhibit the PI3K/AKT/mTOR pathway in MM cells [37, 39]. In the present study, we demonstrated that the combination of metformin and FTY720 significantly suppressed p-PI3k, p-Akt and mTOR levels more than the treatment by metformin or FTY720 alone. Moreover, constitutive activation of AKT greatly repressed the apoptosis induced by metformin and FTY720 in MM cells. These data indicated that the inhibition of the PI3K/AKT/mTOR pathway was involved in the synergistic cytotoxicity of metformin and FTY720.

Amounting evidence indicates the unique redox situation in carcinoma cells and suggests the use of ROS generation as a strategy of anticancer therapy [53]. Disruption of the cellular redox state may represent a critical mechanism behind carcinoma cell death after exposure to anti-tumor agents, either alone or in combination. For instance, the effects of bortezomib in lung cancer cells have been found to rely on the generation of ROS [54]. In addition, the susceptibility of MM cells to arsenic trioxide (As203) has been attributed to free radicalmediated injury [55]. The combination of arsenic trioxide and ascorbic acid-mediated GSH deletion, which might promote the generation of ROS, was clinically effective in the treatment of relapsed or refractory MM. In our study, it appears that synergistic interactions between metformin and FTY720 in MM cells involve, at least partly, enhanced production of ROS and oxidative stress. For example, cotreatment with these agents augmented the proportion of cells displaying increased ROS levels. Moreover, co-administration of the free radical scavenger NAC substantially repressed metformin/FTY720-mediated ROS generation, apoptosis, ER stress and inhibition of the PI3K/AKT/mTOR signaling pathway. NAC also 


\section{Cellular Physiology Cell Physiol Biochem 2018;48:785-800

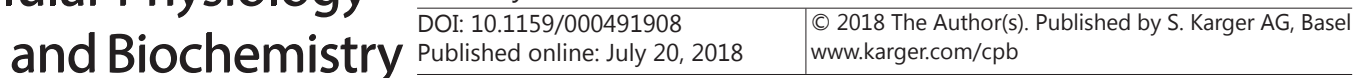 \\ Zhao et al.: Metformin and FTY720 Have Synergistic Effects Against Multiple Myeloma}

attenuated metformin/FTY720-mediated down-regulation of anti-apoptotic Bcl-2 proteins and up-regulation of pro-apoptotic Bax protein.

Our findings are in line with those of other studies. For example, metformin has been found to reversibly inhibit complex I of the mitochondrial respiratory chain, an important source of ROS production [56]. In a recent study, metformin has been found to induce the generation of ROS in colorectal cancer cells [57]. FTY720 was also able to induce apoptosis in oral squamous carcinoma cells via generation of ROS [58]. Thus, the metformin/FTY720 regimen may induce cell death via multiple interacting mechanisms, including increased ROS generation.

To the best of our knowledge, no prior studies investigating the effects of metformin in combination with FTY720 have been performed. In the present study, the effects of metformin in combination with FTY720 and the underlying mechanisms were investigated in vitro in MM cell lines. Many studies have shown that metformin can activate AMPK, which plays an important role in cancer metabolism. However, we failed to show that AMPK was activated (data not shown). We found the synergistic effect of metformin and FTY720 occurred through apoptosis, loss of MMP, ER stress and inhibition of PI3K/AKT/mTOR, all of which rely on the generation of ROS. Our data suggest that combined treatment with metformin and FTY720 could be an effective MM therapy. The present findings could have implications for the design of novel approaches to the treatment of multiple myeloma and possibly other hematopoietic malignancies.

\section{Acknowledgements}

This work was supported by the Funds of the National Natural Science Foundation of China (No. 81472564 for Y. Zhao, No. 81471532 for J. He and No. 31501113 for R. Yu), the Fund for Less Developed Regions of the National Natural Science Foundation of China (No. 81560030 for F. Zi), the Ningbo Natural Science Foundation (No. 2015A610177 for R. Yu), the Natural Science Foundation of Ningbo University (Grant No. XKI15D242 for R. Yu) and the K.C. Wong Magna Fund of Ningbo University.

\section{Disclosure Statement}

No conflict of interests exists.

\section{References}

$>1$ Djulbegovic B, Kumar A: Multiple myeloma: Detecting the effects of new treatments. Lancet 2008;371:1642-1644.

-2 Sukhdeo K, Mani M, Zhang Y, Dutta J, Yasui H, Rooney MD, Carrasco DE, Zheng M, He H, Tai YT, Mitsiades C, Anderson KC, Carrasco DR: Targeting the beta-catenin/tcf transcriptional complex in the treatment of multiple myeloma. Proc Natl Acad Sci U S A 2007;104:7516-7521.

-3 Ludwig H, Durie BG, Bolejack V, Turesson I, Kyle RA, Blade J, Fonseca R, Dimopoulos M, Shimizu K, San Miguel J, Westin J, Harousseau JL, Beksac M, Boccadoro M, Palumbo A, Barlogie B, Shustik C, Cavo M, Greipp PR, Joshua D, Attal M, Sonneveld P, Crowley J: Myeloma in patients younger than age 50 years presents with more favorable features and shows better survival: An analysis of 10549 patients from the international myeloma working group. Blood 2008;111:4039-4047.

-4 Faiman B, Noonan K: New treatments and insights in multiple myeloma. ONS connect 2016;31:4 p following 31.

5 Edgerton DS, Johnson KM, Cherrington AD: Current strategies for the inhibition of hepatic glucose production in type 2 diabetes. Front Biosci 2009;14:1169-1181. 


\section{Cellular Physiology Cell Physiol Biochem 2018;48:785-800

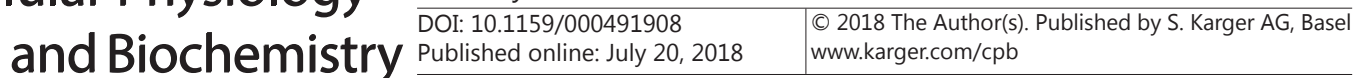 \\ Zhao et al.: Metformin and FTY720 Have Synergistic Effects Against Multiple Myeloma}

6 Boyle P, Boniol M, Koechlin A, Robertson C, Valentini F, Coppens K, Fairley LL, Boniol M, Zheng T, Zhang Y, Pasterk M, Smans M, Curado MP, Mullie P, Gandini S, Bota M, Bolli GB, Rosenstock J, Autier P: Diabetes and breast cancer risk: A meta-analysis. Br J Cancer 2012;107:1608-1617.

7 Fortuny J, Benavente Y, Bosch R, Garcia-Villanueva M, de Sevilla AF, de Sanjose S: Type 2 diabetes mellitus, its treatment and risk for lymphoma. Eur J Cancer 2005;41:1782-1787.

8 Chou YS, Yang CF, Chen HS, Yang SH, Yu YB, Hong YC, Liu CY, Gau JP, Liu JH, Chen PM, Chiou TJ, Tzeng CH, Hsiao LT: Pre-existing diabetes mellitus in patients with multiple myeloma. Eur J Haematol 2012;89:320327.

9 Sleire L, Forde HE, Netland IA, Leiss L, Skeie BS, Enger PO: Drug repurposing in cancer. Pharmacol Res 2017;124:74-91.

10 Samsuri NAB, Leech M, Marignol L: Metformin and improved treatment outcomes in radiation therapy - a review. Cancer Treat Rev 2017;55:150-162.

11 Ikhlas S, Ahmad M: Metformin: Insights into its anticancer potential with special reference to ampk dependent and independent pathways. Life Sci 2017;185:53-62.

12 Pollak MN: Investigating metformin for cancer prevention and treatment: The end of the beginning. Cancer Discov 2012;2:778-790.

13 Libby G, Donnelly LA, Donnan PT, Alessi DR, Morris AD, Evans JM: New users of metformin are at low risk of incident cancer: A cohort study among people with type 2 diabetes. Diabetes Care 2009;32:1620-1625.

14 Fujita T, Inoue K, Yamamoto S, Ikumoto T, Sasaki S, Toyama R, Chiba K, Hoshino Y, Okumoto T: Fungal metabolites. Part 11. A potent immunosuppressive activity found in isaria sinclairii metabolite. J Antibiot 1994;47:208-215.

15 Sonoda Y, Yamamoto D, Sakurai S, Hasegawa M, Aizu-Yokota E, Momoi T, Kasahara T: Fty720, a novel immunosuppressive agent, induces apoptosis in human glioma cells. Biochem Biophys Res Commun 2001;281:282-288.

16 Kim HS, Yoon G, Ryu JY, Cho YJ, Choi JJ, Lee YY, Kim TJ, Choi CH, Song SY, Kim BG, Bae DS, Lee JW: Sphingosine kinase 1 is a reliable prognostic factor and a novel therapeutic target for uterine cervical cancer. Oncotarget 2015;6:26746-26756.

17 Oaks JJ, Santhanam R, Walker CJ, Roof S, Harb JG, Ferenchak G, Eisfeld AK, Van Brocklyn JR, Briesewitz R, Saddoughi SA, Nagata K, Bittman R, Caligiuri MA, Abdel-Wahab O, Levine R, Arlinghaus RB, QuintasCardama A, Goldman JM, Apperley J, Reid A, Milojkovic D, Ziolo MT, Marcucci G, Ogretmen B, Neviani P, Perrotti D: Antagonistic activities of the immunomodulator and pp2a-activating drug fty720 (fingolimod, gilenya) in jak2-driven hematologic malignancies. Blood 2013;122:1923-1934.

18 Azuma H, Takahara S, Ichimaru N, Wang JD, Itoh Y, Otsuki Y, Morimoto J, Fukui R, Hoshiga M, Ishihara T, Nonomura N, Suzuki S, Okuyama A, Katsuoka Y: Marked prevention of tumor growth and metastasis by a novel immunosuppressive agent, fty720, in mouse breast cancer models. Cancer Res 2002;62:1410-1419.

19 Schmid G, Guba M, Papyan A, Ischenko I, Bruckel M, Bruns CJ, Jauch KW, Graeb C: Fty720 inhibits tumor growth and angiogenesis. Transplant Proc 2005;37:110-111.

20 Paugh SW, Payne SG, Barbour SE, Milstien S, Spiegel S: The immunosuppressant fty720 is phosphorylated by sphingosine kinase type 2. FEBS Lett 2003;554:189-193.

-21 Graler MH, Goetzl EJ: The immunosuppressant fty720 down-regulates sphingosine 1-phosphate g-proteincoupled receptors. FASEB J 2004;18:551-553.

22 Patmanathan SN, Yap LF, Murray PG, Paterson IC: The antineoplastic properties of fty720: Evidence for the repurposing of fingolimod. J Cell Mol Med 2015;19:2329-2340.

23 Wu W, Yang Y, Deng G, Ma L, Wei G, Zheng G, Han X, He D, Zhao Y, He J, Cai Z, Yu R: Vernodalol enhances trail-induced apoptosis in diffuse large b-cell lymphoma cells. Mol Carcinog 2017;56:2190-2199.

-24 Balasubramanyam M, Koteswari AA, Kumar RS, Monickaraj SF, Maheswari JU, Mohan V: Curcumininduced inhibition of cellular reactive oxygen species generation: Novel therapeutic implications. J Biosci 2003;28:715-721.

25 Yu R, Yu BX, Chen JF, Lv XY, Yan ZJ, Cheng Y, Ma Q: Anti-tumor effects of atractylenolide i on bladder cancer cells. J Exp Clin Cancer Res 2016;35:40.

-26 Salgame P, Varadhachary AS, Primiano LL, Fincke JE, Muller S, Monestier M: An elisa for detection of apoptosis. Nucleic Acids Res 1997;25:680-681.

-27 Garner TP, Lopez A, Reyna DE, Spitz AZ, Gavathiotis E: Progress in targeting the bcl-2 family of proteins. Curr Opin Chem Biol 2017;39:133-142. 


\section{Cellular Physiology Cell Physiol Biochem 2018;48:785-800

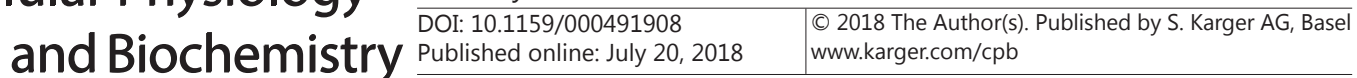 \\ Zhao et al.: Metformin and FTY720 Have Synergistic Effects Against Multiple Myeloma}

28 Yasmeen A, Beauchamp MC, Piura E, Segal E, Pollak M, Gotlieb WH: Induction of apoptosis by metformin in epithelial ovarian cancer: Involvement of the bcl-2 family proteins. Gynecol Oncol 2011;121:492-498.

-29 Kiyota M, Kuroda J, Yamamoto-Sugitani M, Shimura Y, Nakayama R, Nagoshi H, Mizutani S, Chinen Y, Sasaki N, Sakamoto N, Kobayashi T, Matsumoto Y, Horiike S, Taniwaki M: Fty720 induces apoptosis of chronic myelogenous leukemia cells via dual activation of bim and bid and overcomes various types of resistance to tyrosine kinase inhibitors. Apoptosis 2013;18:1437-1446.

- 30 Obeng EA, Carlson LM, Gutman DM, Harrington WJ, Jr., Lee KP, Boise LH: Proteasome inhibitors induce a terminal unfolded protein response in multiple myeloma cells. Blood 2006;107:4907-4916.

31 Ri M, Tashiro E, Oikawa D, Shinjo S, Tokuda M, Yokouchi Y, Narita T, Masaki A, Ito A, Ding J, Kusumoto S, Ishida T, Komatsu H, Shiotsu Y, Ueda R, Iwawaki T, Imoto M, Iida S: Identification of toyocamycin, an agent cytotoxic for multiple myeloma cells, as a potent inhibitor of er stress-induced xbp1 mrna splicing. Blood Cancer J 2012;2:e79.

-32 Hideshima T, Richardson P, Chauhan D, Palombella VJ, Elliott PJ, Adams J, Anderson KC: The proteasome inhibitor ps-341 inhibits growth, induces apoptosis, and overcomes drug resistance in human multiple myeloma cells. Cancer Res 2001;61:3071-3076.

33 Yap TA, Garrett MD, Walton MI, Raynaud F, de Bono JS, Workman P: Targeting the pi3k-akt-mtor pathway: Progress, pitfalls, and promises. Curr Opin Pharmacol 2008;8:393-412.

34 Harvey RD, Lonial S: Pi3 kinase/akt pathway as a therapeutic target in multiple myeloma. Future Oncol 2007;3:639-647.

-35 Bruzzese F, Pucci B, Milone MR, Ciardiello C, Franco R, Chianese MI, Rocco M, Di Gennaro E, Leone A, Luciano A, Arra C, Santini D, Caraglia M, Budillon A: Panobinostat synergizes with zoledronic acid in prostate cancer and multiple myeloma models by increasing ros and modulating mevalonate and p38mapk pathways. Cell Death Dis 2013;4:e878.

-36 Gao L, Gao M, Yang G, Tao Y, Kong Y, Yang R, Meng X, Ai G, Wei R, Wu H, Wu X, Shi J: Synergistic activity of carfilzomib and panobinostat in multiple myeloma cells via modulation of ros generation and erk1/2. Biomed Res Int 2015;2015:459052.

-37 Zi FM, He JS, Li Y, Wu C, Yang L, Yang Y, Wang LJ, He DH, Zhao Y, Wu WJ, Zheng GF, Han XY, Huang H, Yi Q Cai Z: Metformin displays anti-myeloma activity and synergistic effect with dexamethasone in in vitro and in vivo xenograft models. Cancer Lett 2015;356:443-453.

-38 Dalva-Aydemir S, Bajpai R, Martinez M, Adekola KU, Kandela I, Wei C, Singhal S, Koblinski JE, Raje NS, Rosen ST, Shanmugam M: Targeting the metabolic plasticity of multiple myeloma with fda-approved ritonavir and metformin. Clin Cancer Res 2015;21:1161-1171.

-39 Yasui H, Hideshima T, Raje N, Roccaro AM, Shiraishi N, Kumar S, Hamasaki M, Ishitsuka K, Tai YT, Podar K, Catley L, Mitsiades CS, Richardson PG, Albert R, Brinkmann V, Chauhan D, Anderson KC: Fty720 induces apoptosis in multiple myeloma cells and overcomes drug resistance. Cancer Res 2005;65:7478-7484.

$\checkmark 40$ Wuilleme-Toumi S, Robillard N, Gomez P, Moreau P, Le Gouill S, Avet-Loiseau H, Harousseau JL, Amiot M, Bataille R: Mcl-1 is overexpressed in multiple myeloma and associated with relapse and shorter survival. Leukemia 2005;19:1248-1252.

41 Cory S, Roberts AW, Colman PM, Adams JM: Targeting bcl-2-like proteins to kill cancer cells. Trends Cancer 2016;2:443-460.

42 Hetz C, Saxena S: Er stress and the unfolded protein response in neurodegeneration. Nat Rev Neurol 2017;13:477-491.

43 Kim I, Xu W, Reed JC: Cell death and endoplasmic reticulum stress: Disease relevance and therapeutic opportunities. Nat Rev Drug Discov 2008;7:1013-1030.

-44 Kim DS, Jeong SK, Kim HR, Kim DS, Chae SW, Chae HJ: Metformin regulates palmitate-induced apoptosis and er stress response in hepg2 liver cells. Immunopharmacol Immunotoxicol 2010;32:251-257.

45 Yang J, Wei J, Wu Y, Wang Z, Guo Y, Lee P, Li X: Metformin induces er stress-dependent apoptosis through mir-708-5p/nnat pathway in prostate cancer. Oncogenesis 2015;4:e158.

-46 Lin YC, Wu MH, Wei TT, Lin YC, Huang WC, Huang LY, Lin YT, Chen CC: Metformin sensitizes anticancer effect of dasatinib in head and neck squamous cell carcinoma cells through ampk-dependent er stress. Oncotarget 2014;5:298-308.

-47 Chen Q Thompson J, Hu Y, Das A, Lesnefsky EJ: Metformin attenuates er stress-induced mitochondrial dysfunction. Transl Res 2017;190:40-50. 


\section{Cellular Physiology Cell Physiol Biochem 2018;48:785-800 \begin{tabular}{l|l} 
DOI: 10.1159/000491908 & O 2018 The Author(s). Published by S. Karger AG, Basel \\
www.karger.com/cpb
\end{tabular}

48 Moon JS, Karunakaran U, Elumalai S, Lee IK, Lee HW, Kim YW, Won KC: Metformin prevents glucotoxicity by alleviating oxidative and er stress-induced cd36 expression in pancreatic beta cells. J Diabetes Complications 2017;31:21-30.

49 Vincenz L, Jager R, O’Dwyer M, Samali A: Endoplasmic reticulum stress and the unfolded protein response: Targeting the achilles heel of multiple myeloma. Mol Cancer Ther 2013;12:831-843.

50 Vanhaesebroeck B, Stephens L, Hawkins P: Pi3k signalling: The path to discovery and understanding. Nat Reviews Mol Cell Biol 2012;13:195-203.

-51 Hu P, Han Z, Couvillon AD, Exton JH: Critical role of endogenous akt/iaps and mek1/erk pathways in counteracting endoplasmic reticulum stress-induced cell death. J Biol Chem 2004;279:49420-49429.

52 Khwaja A: Pi3k as a target for therapy in haematological malignancies. Curr Top Microbiol Immunol 2010;347:169-188.

53 Ozben T: Oxidative stress and apoptosis: Impact on cancer therapy. J Pharm Sci 2007;96:2181-2196.

54 Ling YH, Liebes L, Zou Y, Perez-Soler R: Reactive oxygen species generation and mitochondrial dysfunction in the apoptotic response to bortezomib, a novel proteasome inhibitor, in human h460 non-small cell lung cancer cells. J Biol Chem 2003;278:33714-33723.

55 Grad JM, Bahlis NJ, Reis I, Oshiro MM, Dalton WS, Boise LH: Ascorbic acid enhances arsenic trioxideinduced cytotoxicity in multiple myeloma cells. Blood 2001;98:805-813.

56 Bridges HR, Jones AJ, Pollak MN, Hirst J: Effects of metformin and other biguanides on oxidative phosphorylation in mitochondria. Biochem J 2014;462:475-487.

57 Mogavero A, Maiorana MV, Zanutto S, Varinelli L, Bozzi F, Belfiore A, Volpi CC, Gloghini A, Pierotti MA, Gariboldi M: Metformin transiently inhibits colorectal cancer cell proliferation as a result of either ampk activation or increased ros production. Sci Rep 2017;7:15992.

58 Bai LY, Chiu CF, Chiu SJ, Chu PC, Weng JR: Fty720 induces autophagy-associated apoptosis in human oral squamous carcinoma cells, in part, through a reactive oxygen species/mcl-1-dependent mechanism. Sci Rep 2017;7:5600. 